\title{
ANALISIS PRINSIP KERJA SAMA DALAM ACARA KOMEDI EXTRAVAGANZA
}

\section{ANALYSIS OF COOPERATION PRINCIPLES IN EXTRAVAGANZA COMEDY EVENTS}

\author{
Faizal Arvianto \\ Universitas Timor \\ faizal_arvianto@yahoo.com
}

\begin{abstract}
Abstrak
Dalam kajian berbahasa terdapat kajian tentang penggunaan bahasa yang dimaksudkan sebagai upaya membimbing para peserta percakapan agar dapat melakukan percakapan secara kooperatif yaitu kajian pragmatic khususnya pada bagian prinsip kerja sama. Grice membagi empat maksim yang membangun prinsip kerja sama. Keempat maksim tersebut ialah maksim Kualitas, kuantitas, hubungan, dan cara. Objek kajian dalam analisis ini adalah acara komedi Extravaganza segmen "Cinta di Restoran" yang tayang di Trans TV. Dari hasil analisis menggunakan prinsip kerja sama diperoleh data percakapan yang menunjukkan adanya maksim kualitas (Maxime der Qualität) sebanyak 4 percakapan, 3 percakapan melanggar maksim dan 1 tidak melakukan pelanggaran maksim. Sedangkan untuk maksim kuantitas (Maxime der Quantität) diperoleh data sebanyak 12 percakapan, 2 diantaranya melanggar maksim dan 10 tidak melakukan pelanggaran maksim. Selanjutnya untuk maksim relevansi (Maxime der Relevan») diperoleh data sebanyak 3 percakapan dan semuanya dinyatakan relevan/tidak melanggar maksim. Sedangkan untuk maksim cara (Maxime der Modalität) didapat 2 percakapan, 1 percakapan menunjukkan adanya pelanggaran maksim dan 1 sisanya tidak menunjukkan adanya pelanggaran maksim.
\end{abstract}

Kata kunci: prinsip kerja sama, makasim, komedi, pragmatik

\begin{abstract}
In language studies there is a study of the use of language which is intended as an effort to guide conversation participants to be able to carry out cooperative conversations, namely pragmatic studies, especially in the part of the principle of cooperation. Grice divides four maxims which establish the principle of cooperation. The four maxims are the maxims of Quality, quantity, relationships, and ways. The object of the study in this analysis is the comedy Extravaganza program "Love in the Restaurant" which aired on Trans TV. From the results of the analysis using cooperative principles, conversational data were obtained which showed the existence of quality maxims (Maxime der Qualität) in 4 conversations, 3 conversations violating maxims and 1 not violating maxims. Whereas for the maximum quantity (Maxime der Quantität) there are 12 conversations, 2 of which violate maxims and 10 do not violate maxims. Furthermore, for the maximal relevance (Maxime der Relevanz) data obtained as many as 3 conversations and all are declared relevant / not violating the maxim. Whereas for the maximal means (Maxime der Modalität) there were 2 conversations, 1 conversation showed a violation of maxims and the remaining 1 did not show violations of maxims.
\end{abstract}

Keywords: the principle of cooperation, makasim, comedy, pragmatics 


\section{PENDAHULUAN}

Komunikasi merupakan kegiatan sosial. Di dalam berbicara tentunya penutur dan lawan tutur harus saling bekerjasama untuk mendapatkan tujuan dan maksud yang diharapkan. Namun, pada kenyataannya penutur dan lawan tutur melanggar prinsip kerjasama yang seharusnya dipatuhi dalam bertutur. Seperti halnya aktivitas-aktivitas sosial yang lain, kegiatan berbahasa baru terwujud apabila manusia terlibat di dalamnya. Di dalam berbicara, penutur dan mitra tutur menyadari bahwa adanya kaidah-kaidah yang mengatur tindakannya, penggunaan bahasanya, dan interpretasinya terhadap tindakan dan ucapan lawan tuturnya. Setiap peserta tindak tutur bertanggung jawab terhadap tindakan dan penyimpangan terhadap kaidah kebahasaan di dalam interaksi lingual itu.

Penutur dalam bertindak tutur berusaha agar semua yang disampaikannya dapat dengan mudah dipahami dan tidak merugikan mitra tutur untuk mencapai tujuan. Tujuan tersebut menurut Grice (dalam Yuniarsih, 2011: 16) meliputi: (1) menyampaikan informasi, (2) meminta informasi, (3) memerintah, (4) menolak, (5) mengekspresikan perasaan, (6) mengangkat, (7) meminta perhatian, (8) menyampaikan permintaan, (9) meminta penegasan, (10) menunjukkan rasa solidaritas, dan (11) mengungkapkan terima kasih kepada mitra tuturnya. Untuk itu, penutur harus menaati aturan-aturan yang ada dalam sebuah tuturan. Aturan-aturan yang ada dalam sebuah tuturan disebut sebagai prinsip kerja sama dan prinsip sopan santun.

\section{Prinsip Kerja Sama}

Grice (dalam Rustono, 1999: 53) menjelaskan tentang prinsip kerja sama sebagai pokok subteori tentang penggunaan bahasa. Subteori tentang penggunaan bahasa itu dimaksudkan sebagai upaya membimbing para peserta percakapan agar dapat melakukan percakapan secara kooperatif. Grice membagi empat maksim yang membangun prinsip kerja sama. Keempat maksim tersebut ialah maksim Kualitas, kuantitas, hubungan, dan cara.

\section{Maksim Kualitas}

Penutur berbicara sesuai dengan apa yang dianggap benar, dan tidak akan menuturkan sesuatu yang mereka anggap salah. Kebenaran informasi tersebut didasarkan pada aspek kejujuran. Kebenaran tersebut hendaknya dapat dibuktikan dengan bukti-bukti yang ada. Pernyataan tersebut sesuai dengan pendapat Grice dalam artikelnya (1975: 159) yang menegaskan sebagai berikut:

Try to make your contribution one that is true.

(Cobalah untuk membuat suatu informasi yang benar).

Do not say what you believe to be false.

(Jangan mengatakan sesuatu yang kamu yakini salah).

\section{Maksim Kuantitas}

Ketika melakukan kegiatan berkomunikasi, pelaku tutur perlu memperhatikan aspek keinformatifan yang ada dalam tuturan tersebut. Maksud dari keinformatifan tersebut ialah, para peserta tutur tidak berkata terlalu lebar, maupun singkat. Pernyataan tersebut sesuai dengan pendapat Grice yang memberikan batasan maksim kuantitas. Lebih lanjut Grice (1975: 159) memberikan batasan sebagai berikut:

Make your contribution as informative as is required (for the current purposes of the exchange). 
"Buatlah percakapan yang informatif seperti yang diminta (dengan maksud pergantian percakapan yang sedang berlangsung)".

\section{Maksim Hubungan}

Dalam bertutur, peserta tutur hendaknya juga memperhatikan aspek relevansi. Aspek relevansi ini berkaitan dengan maksim hubungan atau maksim relevansi. Dalam maksim ini, setiap penutur diwajibkan untuk memberikan kontribusi yang sesuai atau gayut dengan masalah yang sedang dibicarakan. Pernyataan tersebut sesuai dengan pendapat yang juga memberikan batasan-batasan tentang maksim hubungan. Grice (1975: 159) menegaskan maksim hubungan sebagai berikut:

Relation: Be relevant

(Hubungan: Relevanlah).

\section{Maksim Cara}

Aspek lain yang perlu diperhatikan dalam tuturan ialah aspek kejelasan. Aspek kejelasan tersebut termasuk ke dalam maksim cara. Maksim ini menginginkan setiap penutur berbicara secara langsung, runut, tidak kabur, dan tidak berlebih-lebihan.

Grice memberikan batasannya (1975: 159) sebagai berikut:

Be brief (avoid unnecessary prolixity).

"Buatlah singkat (hindarkan panjang lebar yang tidak perlu)".

Be orderly.

(Buatlah secara teratur).

Apabila seorang penutur mematuhi maksim cara, ia akan mengeluarkan tuturan yang bernada positif daripada tuturan yang bernada negatif, sehingga ia terbebas dari ketidakjelasan pernyataannya.

Contoh:

"Anjing kami jantan"

"Anjing kami bukan betina"

Kegiatan berkomunikasi menuntut adanya kejelasan tuturan penutur, penutur dituntut memberikan informasi yang terbebas dari ketaksaan atau ambigu. Dalam hal ini suatu konteks jangan sampai terlepas dari tiap tuturan. Menurut Corder (dalam Thomas, 1995: 14) bahwa kalimat berterima yang dikeluar dari penutur asli akan menjadi ambigu ketika dihilangkan konteksnya. Contoh: Penutur mengacu pada kota Jenewa:

"Ini adalah suatu kota tempat bank-bank di sepanjang sungai, yang mempunyai makna berbeda dari biasanya" (Thomas, 1995: 16).

Bila konteks yang dimaksud kota Jenewa dihilangkan, maka akan terjadi ketaksaan berupa kata bank. Bank sendiri mempunyai dua makna, yakni sebuah institusi dan tepi sungai (Inggris), tetapi makna yang dimaksud oleh penutur di sini ialah sebuah institusi. Maksim cara juga menuntut penutur untuk berbicara secara singkat. Maksud tuturan yang singkat ialah, sebaiknya tuturan tersebut tidak bertele-tele. Contohnya lebih baik mengatakan "Nyalakan kipas anginnya" dibanding dengan "Berjalanlah ke arah kipas angin, sambungkan kabel, kemudian tekan tombol nomor tiga".

Tidak kalah pentingnya dalam maksim cara ialah penutur diharapkan bertutut secara urut. Dalam menggabungkan urutan tersebut, diharapkan mengikuti kaidah yang berlaku berupa penggunaan kata gabung. "Sinta berpamitan pada orang tuanya 
kemudian berangkat sekolah". Kata gabung yang digunakan ialah kata "kemudian".

\section{Pelanggaran dalam Prinsip Kerja Sama}

Thomas merupakan penganut teori ketidakpatuhan/pelanggaran Grice. Thomas dalam bukunya (1995) memberikan teori tentang beberapa jenis ketidakpatuhan maksim yang dapat memperkuat teori Grice yang lebih dahulu muncul.

\section{Menyesatkan maksim}

Menurut Grice (dalam Thomas, 1995: 72), jika penutur melakukan "violate" terhadap suatu maksim, maka besar kemungkinannya bahwa tuturannya itu menyesatkan karena ada informasi yang disembunyikan. Maksudnya penutur mengatakan sesuatu yang benar, namun dalam tuturannya tersebut membangkitkan implikatur yang menyesatkan atau salah. Thomas menjabarkan teori Grice ini menjadi "menyesatkan suatu maksim" yakni ketidakpatuhan yang dilakukan karena adanya informasi yang disembunyikan.

\section{Membatalkan maksim}

Seorang penutur memilih keluar dari maksim dengan menampakan ketidakmauannya untuk bekerja sama dalam percakapan yang diperlukan. Penutur membatalkan suatu maksim dengan cara menunjukkan ketidakmauannya untuk bekerja sama sebagaimana yang dibutuhkan maksim. Sebagai contoh, dengan alasan hukum atau etika, penutur sebagai pendeta, konsultan, wartawan, atau polisi menolak menyampaikan informasi secara terang- terangan. Hal tersebut terjadi dikarenakan besar kemungkinan akan menyakiti perasaan pihak ketiga atau menempatkan mereka dalam bahaya.

\section{Benturan antar maksim}

Dalam situasi ini, penutur dengan sendirinya tidak mampu memenuhi maksim kualitas dan kuantitas secara bersamaan. Penutur mengalami dilema yang tidak mampu memberikan informasi secara tepat pada mitra tuturnya.

\section{Mencemooh maksim}

Situasi ini menurut Grice ialah ketika seorang penutur dengan terang-terangan sengaja untuk tidak mematuhi maksim, bukan untuk menipu atau menyesatkan, tetapi untuk menyarankan kepada mitra tuturnya untuk mencari makna lain yang berbeda dengan yang diucapkan, atau makna tambahan lain yang lebih tepat. Dari beberapa uraian tentang maksim prinsip kerja sama tersebut, dapat ditarik simpulan bahwa terdapat dua hal yang berbeda antara violate (melanggar) dan flout (mencemooh). Keduanya sama-sama bentuk pelanggaran, hanya saja flout penutur melakukannya dengan terang- terangan, untuk membuat mitra tuturnya menangkap implikatur yang ada. Istilah flout mempunyai nama lain exploited (mengeksploitasi maksim).

\section{HASIL DAN PEMBAHASAN}

\section{Maksim Kualitas}

Adalah maksim percakapan yang mewajibkan setiap peserta percakapan mengatakan hal yang sebenarnya. Dialog yang termasuk dalam maksim kuantitas pada tayangan Ekstravaganza tersebut adalah:

(1) Tora : "Nanti dulu. Km yakin itu ingus?"

Mike : "Yakin abang, itu ingus abang." 
Tora : "Anggap aja itu bonus dari abang."

Mike memberikan kontribusi yang tidak melanggar maksim kualitas. Karena Mike telah mengatakan hal yang sebenarnya.

(2) Pelayan: "Orange white satu yah, masnya mau pesan apa?"

Tora : "Saya mau minum yang sangat berkelas nih "beras kencur".

(3) Tora : "Kalau gitu saya mau satu mas."

Pelayan: "Pesan yang apa? Martin??"

Tora : "Air putih."

Kedua dialog tersebut melanggar maksim kualitas. Hal itu ditunjukkan dengan jawaban Tora dengan tujuan untuk mendapatkan efek lucu. Kelucuan itu terdapat pada minuman berkelas beras kencur dan air putib.

(4) Pelayan: "Sapi lokal atau sapi impor?"

Tora : "Yang lokal dong, yang lebih nikmat."

Pelayan: "Oke. Ehh yang lokal mau jawa atau bali?"

Tora : "Jawa."

Tora memberikan kontribusi yang melanggar maksim kualitas. Hal ini ditunjukkan dengan jawaban Tora yang menginginkan efek lucu. Seperti terlihat pada yang lokal dong, yang lebih nikmat.

\section{Maksim Kuantitas}

Adalah maksim yang menghendaki setiap peserta pertuturan memberikan kontribusi yang secukupnya atau sebanyak yang dibutuhkan oleh lawan bicaranya. Dialog yang termasuk dalam maksim kuantitas pada tayangan Ekstravaganza tersebut adalah:

(5) Tora : "Abang bawa kamu kesini karena sekarang adalah hari jadi kita."

Mike : "Oh begitu."

Dialog di atas tidak melanggar maksim, karena dialog antara Tora dan Mike terdapat kerjasama yang baik. Mike telah memberikan kontribusi yang secara kuantitas memadai dan mencukupi.

(6) Tora : "Kita udah setahun jadian sayang."

Mike : "Iya yah, gag kerasa ya udah setahun kita pacaran bang."

Dialog di atas mengalami pelanggaran maksim, karena dialog antara Tora dan Mike tidak terlihat adanya kerjasama yang baik. Ini dikarenakan Mike memberikan kontribusi yang berlebihan yang tidak diperlukan Tora.

(7) Mike : "Terimaksih mas."

Pelayan: "Sama-sama mbak."

Dialog di atas tidak melanggar maksim, karena dialog antara Mike dan pelayan terdapat kerjasama yang baik. Pelayan telah memberikan kontribusi yang secara kuantitas cukup memadai dan mencukupi dari tuturan Mike.

(8) Pelayan: "Mas, disini tidak ada minuman beras kencur."

Tora : "Gag ada beras kencur yah, berarti diganti susu soda."

Dialog di atas mengalami pelanggaran maksim, karena dialog antara pelayan dan Tora tidak terlihat adanya kerjasama yang baik. Ini dikarenakan Tora memberikan kontribusi yang berlebihan. 
3. Maksim Relevansi

Maksim relevansi mengharuskan setiap peserta percakapan memberikan kontribusi yang relevan dengan masalah pembicaraan.

(9) Pelayan: "Boleh saya menghidupkan lilin ini?"

Mike : "Silahkan."

Jawaban yang diberikan Mike relevan dengan pertanyaan pelayan.

(10) Mike : "Mas, saya kan sudah bilang terimaksih beberapa kali. Kenapa mas gag pergi-pergi sih?"

Pelayan: "Abis mbaknya cantik si. Eh iyah mau pesan minum apa?"

Jawaban pelayan dapat dianggap sebagai suatu jawaban yang melanggar maksim relevansi. Hal ini dikarenakan pelayan memberikan jawaban yang bersifat "menggoda" Mike karena kecantikannya. Selain itu godaan pelayan juga ditujukan untuk "mencairkan" suasana. Pernyataan pelayan dapat dikatakan relevan bila jawaban tersebut memang menginterpretasikan sebagai suatu keterangan mengapa Pelayan tidak dapat menjawab pertanyaan Mike yang sebenarnya.

\section{Maksim Pelaksanaan/cara}

Adalah maksim yang mengharuskan setiap peserta percakapan berbicara secara langsung, tidak kabur, tidak taksa, dan tidak berlebih-lebihan, serta runtut. Dialog yang termasuk dalam maksim kuantitas pada tayangan Ekstravaganza tersebut adalah:

(11) Pelayan: "Nah itu tahu. Disini itu adanya Whine, Sampaigne, Martini. Jadi mau pesan apa?”

Tora : "Kalau gitu saya mau satu mas."

Jawaban Tora merupakan jawaban yang melanggar maksim pelaksanaan, karena jawaban yang diberikan Tora kabur, tidak jelas dalam memesan minuman yang diinginkan sehingga tidak dimengerti oleh Pelayan.

(12) Mike : "Abang, kenapa sih abang ngajak aku makan ke tempat yang romantis begini ?"

(13) Tora : "Abang bawa kamu kesini karena sekarang adalah hari jadi kita."

Jawaban Tora merupakan jawaban yang tidak melanggar maksim pelaksanaan. Karena Tora memberikan kontribusi secara langsung, tidak berlebih-lebihan serta runtut.

\section{SIMPULAN}

Dari tayangan komedi Extravaganza yang telah dianalisis dengan menggunakan prinsip kerjasama, didapat keempat maksim yang selalu muncul dalam berbagai tuturan. Pelanggaran maksim-maksimnya juga tidak dapat dihindarkan selama tuturan berlangsung. Selain itu, pelanggaran maksim-maksim yang dilakukan oleh para penutur dalam berbagai tayangan tersebut dilakukan guna menciptakan kelucuan. Dari analisis yang sudah dilakukan, diperoleh data percakapan yang menunjukkan adanya maksim kualitas (Maxime der Qualität) sebanyak 4 percakapan. Dimana ada 3 percakapan yang melanggar maksim dan 1 percakapan tidak melakukan pelanggaran maksim. Sedangkan untuk maksim kuantitas (Maxime der Quantität) diperoleh data percakapan sebanyak 12 percakapan, 2 diantaranya melanggar maksim dan 10 percakapan diketahui tidak melakukan pelanggaran maksim. 
Selanjutnya untuk maksim relevansi (Maxime der Relevang) diperoleh data percakapan sebanyak 3 percakapan, 2 percakapan di antaranya dapat dikatakan relevan dan 1 percakapan dinyatakan tidak relevan/melanggar maksim relevansi. Sedangkan untuk maksim pelaksanaan/cara (Maxime der Modalität) didapat 2 percakapan, 1 percakapan menunjukkan adanya pelanggaran maksim dan 1 percakapan sisanya tidak menunjukkan adanya pelanggaran maksim,

\section{DAFTAR PUSTAKA}

Grice, H.P. 1975. "Logic and Conversation" dalam Cole; P7J.L. Morgan. 1975. Syntax and Semantics Vol 3: Speech Acts. New York: AkademiC Press.

Leech, Geoffrey. 1993. Prinsip-Prinsip Pragmatik. Jakarta: Universitas Indonesia (UI-Press).

Rustono. 1999. Pokok-pokok Pragmatik. Semarang: CV IKIP Semarang.

Thomas, Jenny. 1995. Meaning in Interaction: an Introduction to Pragmatics. New York: Adison Wesley Long-man Publishing.

Wijana, I. Dewa Putu. 1996. Dasar-Dasar Pragmatik. Yogyakarta: ANDI.

Yuniarsih, Nanik. 2011. Ketidakpatuban Maksim Prinsip Kerja Sama dalam Acara "Opini" di TV ONE: Sebuah Kajian Pragmatik (Tesis). Surakarta: FSSR UNS. 
